\title{
The Relationship Between Couples' Gender-Role Attitudes Congruence and Wives' Family Interference with Work
}

This article was published in the following Dove Press journal: Psychology Research and Behavior Management

\author{
Yunyang $\mathrm{Hu}^{\prime}$ \\ Jiamin $\mathrm{Li} \mathbb{D}^{\prime}$ \\ Maolin $\mathrm{Ye}^{\mathrm{I}}$ \\ Hanlin Wang ${ }^{2}$ \\ 'School of Management, Jinan University, \\ Guangzhou, People's Republic of China; \\ ${ }^{2}$ School of Education, Hebei Normal \\ University, Shijiazhuang, People's Republic \\ of China
}

Background: Previous research on female employees' family interference with work (FIW) has demonstrated that such conflict is affected by their or their spouses' gender-role attitudes. However, few studies have considered the perspective of husbands-wives congruence, which is further meaningful of the research on FIW. The purpose of this paper is to examine the relationship between husband-wife congruence of gender-role attitudes and wife's FIW.

Methods: Data were collected from 148 husband-wife dyads from eight companies in China. The average age of the husbands was 31.86 years $(S D=8.75)$ and that of the wives was $28.39(S D=6.38)$. The hypotheses were tested by the combination of polynomial regression and response surface methodology.

Results: Four results were drawn. First, wives' role overload is lower when husbands and wives are aligned in terms of gender-role attitudes than when they are not aligned $\left(a_{4}=0.53\right.$, $p<0.01)$. Second, on the condition of husband-wife congruence, role overload is positively correlated with their gender-role attitudes $\left(a_{1}=0.59, p<0.001\right)$. Third, on the condition of incongruence, wives' role overload is stronger when husbands' traditional gender-role attitudes are higher than wives', compared to when wives' traditional gender-role attitudes are higher than husbands' $\left(a_{3}=0.23, p<0.05\right)$. Fourth, role overload mediates the relationship between husband-wife congruence of gender-role attitudes and wives' FIW (indirect effect $=0.15 ; 95 \%$ CI $[0.05,0.27])$.

Conclusion: Guided by the role theory, the current study suggests that the husband-wife incongruence of gender-role attitudes augments wives' role overload and further leads to FIW.

Keywords: husband-wife congruence, gender-role attitudes, role overload, FIW, polynomial regression

\section{Introduction}

The traditional family pattern where the male is the breadwinner and the female is the homemaker has become less popular over the last few decades. Nowadays, women are becoming an essential part of the labor market. ${ }^{1}$ However, despite the fact that women are involved in the labor role increasingly, family matters are still regarded as women's responsibility in general society. ${ }^{2}$ Since women face demands from both the family and the workplace, they often experience intense role conflicts. ${ }^{3}$ Upon this background, the work-family conflict has become a heated topic in the field of organizational behavior. Work-family conflict refers to a form of inter-role conflict in which the role demands from the work and family domains are
Correspondence: Maolin Ye

School of Management, Jinan University, Guangzhou 5I063I, People's Republic of China

Tel + 8613922285577

Email maolinye@I63.com 
mutually incompatible in some respect. That is, participation in the work (family) role is made more difficult by virtue of participation in the family (work) role. ${ }^{4}$

It includes two dimensions: work interference with family (WIF) and family interference with work (FIW). ${ }^{4}$ FIW has been an oft-studied phenomenon, probably because it influences important organizational and jobrelated outcomes. Empirical studies have provided ample evidence that FIW has a negative effect on job satisfaction, organizational commitment, and employees' overall performance. ${ }^{5,6}$ Thus, exploring how to deal with women's FIW has a significant practical implication.

Some scholars suggested that wives' gender-role attitude is an important factor influencing their FIW. ${ }^{7}$ Gender-role attitudes reflect the beliefs about ideal role behaviors for men and women, which particularly concern their ideal involvement in family and work roles. ${ }^{8}$ Gender-role attitudes are often conceptualized as representing a continuum with traditional vs egalitarian at the endpoints. ${ }^{9}$ Those with traditional gender-role attitudes claim that women are best suited for the family role and define women's responsibilities mainly on the basis of being a mother and housewife, rather than the basis of occupational roles. ${ }^{10}$ On the contrary, those with egalitarian gender-role attitudes believe that both men and women should be recognized equally in their participation and contribution to work and family. ${ }^{11}$ Previous studies have found that working women who have traditional gender-role attitudes tend to put much more effort and resources into the family role; therefore, they are more likely to experience strong FIW. ${ }^{12}$ However, other scholars point out that married female employees with egalitarian gender-role attitudes are much more likely to experience strong FIW. ${ }^{7}$ Although controversial viewpoints exist, scholars still agree that women's gender-role is an important factor influencing FIW.

Recently, literature has switched its attention toward the influence of a husband, as the significant other, on his wife's FIW. ${ }^{13}$ Recent studies have found that husbands with the traditional gender-role attitude dedicate less time and energy to family and, at the same time, create greater expectations regarding their wives' family role, which increases wives' burden of the family role. As a result, it leads to work-family conflict for wives. ${ }^{9}$

Although many studies have examined the impact of the gender-role attitude of husbands or wives separately in terms of wives' work-family conflicts, they overlooked how working women's gender-role attitude and husbands' gender-role attitude could jointly influence their role conflict. Researchers pointed out that an individual would experience role conflict when he/she was expected to do something that deviates from his/her personal values. ${ }^{14}$ Since the wife's gender-role attitude represents her own values and the husband's represents role expectations for the wife, does the wife's FIW occur when the couple's gender-role attitudes are inconsistent?

In addition, most empirical studies describe the direct impact of wives and husbands' gender-role attitudes on their work-family conflicts. However, the underlying mechanism remains unknown. Scholars have pointed out that the emergence of FIW is due to the fact that individuals play different roles in different contexts, such as the workplace and the family. Because of competitive needs for multiple roles, the time and energy devoted to one role make it difficult to fulfil the requirements of another role. Role overload is a concept that describes the perception that individuals are unable to meet all the demands within a domain. ${ }^{15}$ Therefore, we believe that role overload is likely to mediate the relationships between the congruence of couples' attitudes toward genderrole and wives' FIW. In summary, this paper proposes the theoretical model shown in Figure 1. Our study aimed to advance existing literature by further focusing on the following two aspects.

First, although past literature has explored the impact of a couple's gender-role attitude on wives' FIW, those studies were based on one perspective (either the

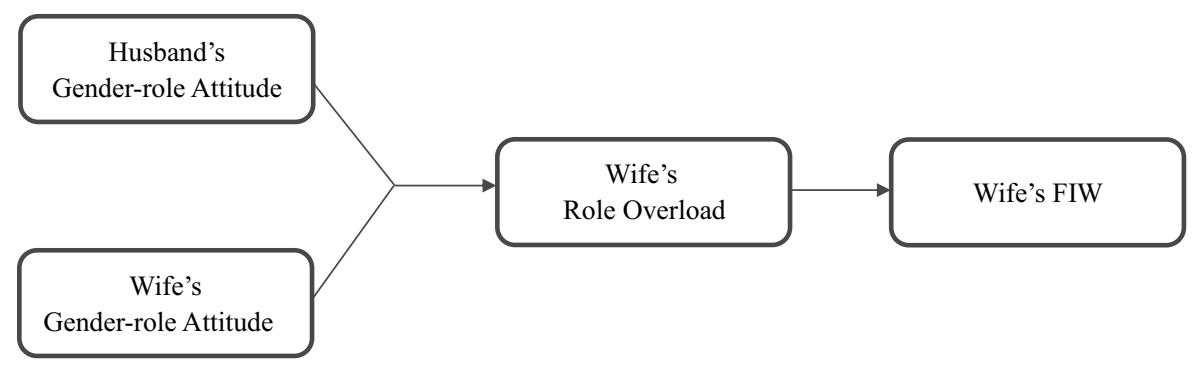

Figure I Research framework. 
husband's or the wife's perspective). Conversely, the current study applied polynomial regression and response surface analysis to explore the relationship between the congruence of both husbands' and wives' gender-role attitudes and wives' FIW from a dyadic perspective, which further reveals the relationship between gender-role attitudes and wives' FIW.

Second, this paper further aims to elucidate the potential mechanism linking congruence of couple's gender-role attitudes and wives' FIW, which is an important complement to previous research.

\section{Theories and Hypotheses}

\section{The Four Different Scenarios of}

\section{Congruence and Incongruence in Husband-Wife Gender-Role Attitudes}

According to various levels of husbands' and wives' attitudes toward gender-roles, the study has identified the following four different matching scenarios as shown in Figure 2: traditional-traditional; egalitarian-egalitarian; traditional-egalitarian; egalitarian-traditional. The former two aspects fall into the category of congruence and the latter fall into the incongruence category. When discussing the relationship between the congruence of couple's genderrole attitudes and the wife's role overload, it is necessary to address some issues. First of all, we examine whether the wife's role overload is lower in the scenarios of congruence than in an incongruence context. Second, for the two congruence scenarios, whether the wife's role overload is lower in the egalitarian-egalitarian scenario than in the traditional-traditional one. Finally, in terms of the two incongruence scenarios, whether the wife's role overload is higher when the husband holds a traditional gender-role attitude and the wife holds an egalitarian gender-role attitude in comparison with the opposite.

\section{Gender-Role Attitude Congruence Effects on the Wife's Role Overload}

Role theory suggests that role strain depends on the individuals' perception of congruence between their selfconcepts and role expectations (called "self-role congruence", $\left.{ }^{16}\right)$. Role expectations are social requirements for the specific role symbolizing the "norm" of role behavior. When the self-concepts and role expectations are consistent, the performance of the role will be more "effective, proper, and appropriate". ${ }^{17}$ Conversely, when there is an inconsistency between the two, the individual will experience violation of the role's "norm." To meet the role expectations, there are role pressures that then arise. ${ }^{18}$

Applying role theory to this study, the wife's gender-role attitude could be viewed as the self-concept. In addition, the spouse's gender-role attitude toward an individual belongs to a kind of sex-role expectation. ${ }^{19}$ Therefore, the husband's gender-role attitude toward women could be viewed as the role expectation for the wife. When couples' gender-role attitudes are inconsistent, the wife has to serve the extra expectation from her husband in addition to the personal demands of her own role. The increase in role demand will lead to the wife's role overload. Rather, when a couple has a similar gender-role attitude indicating the consistency of personal value and the role demands from the significant other, an individual can simply fulfill her demands for role acting, thus decreasing the possibility of the role overload phenomenon. On the above basis, the first hypothesis of this study is as follows:

Hypothesis 1 (H1). Role overload is higher when husbands and wives are incongruent at the level of gender-role attitude than when they are congruent.

Next, we will turn to the context of congruence. It is necessary to clarify that husbands and wives can be either

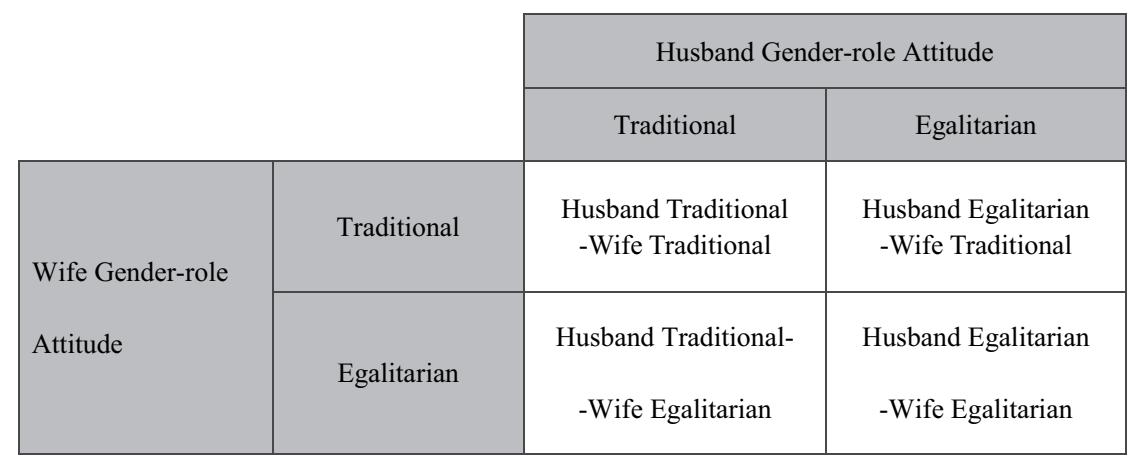

Figure 2 Four different scenarios of congruence in husband-wife gender-role attitudes. 
congruent as traditional or egalitarian in their gender-role attitudes. In this case, we assumed that the wife's role overload in the egalitarian-egalitarian context is lower compared to the traditional-traditional context. Under egalitarian-egalitarian conditions, the desire of the wife to devote to the family role and the demands from her husband is not strong, which decreases the possibility of role overload in the family. Besides, when the husband holds the egalitarian view of gender roles, he shows more support for his wife's work-related development and, as a result, he will support his wife as well when it comes to family-related aspects. For example, the husband will invest more in the family domain, such as housework and childcare, which are traditionally believed to be women's responsibilities. ${ }^{9}$ Previous studies have also found that family support for their personal career has an important impact on the psychological pressure of female employees in Chinese society. Specifically, family support can reduce role overload for women in China and Hong Kong. ${ }^{20}$

On the contrary, when both the husband and the wife hold the traditional gender-role view, the wife is more willing to invest in the family role. In addition, the husband has a higher expectation of wife's family role. When the role demand is strong, the wife experiences more role pressure from internal and external factors, which are more likely to increase role overload. Besides, the husband with a traditional gender-role attitude sets aside the duties that his believes are supposed to be his wife's family role demand, thereby increasing the wife's family role overload. $^{9}$ As a result, compared to an egalitarianegalitarian situation, the wife in a traditional-traditional situation invests much more in the family role, resulting in her being role overloaded. Based on these considerations, the second hypothesis is as follows:

Hypothesis 2 (H2). Wives' role overload is higher when both the husband and the wife have the traditional genderrole attitude than when they have the egalitarian one.

Moreover, we will discuss the context when a couple has inconsistency in their gender-role attitudes. This involves two different situations: (1) husband is traditional and wife is egalitarian and (2) husband is egalitarian and wife is traditional. According to the prior study, spousal support (eg, instrumental aid, emotional concern, information, and appraisal functions) for an individual has a strong negative correlation with the individual's role stress in the family domain. ${ }^{21}$ Specifically, with spousal support, the wife's role demands in the family domain will be fulfilled effectively; therefore, the individual will experience a reduction in role overload within the family domain. Based on this logic, when the husband has an egalitarian gender-role attitude while wife has a traditional one, the husband tends to believe that the housework in the family is not the responsibility of his wife only but is more likely to help by sharing family duties, so that the wife can have support and relief in the family domain. Under this condition, the wife's resource consumption in the family domain decreases and reduces role overload. Moreover, although wives with the traditional gender-role attitude still want to shoulder the family responsibility, their self-expectations regarding their own role in the family domain exceed societal expectations from their significant others, thus making the role demand easier to meet, which, to a large extent, reduces the possibility of role overload experience. $^{22}$

On the contrary, when the husband holds a stronger traditional attitude while his wife is the opposite, the husband believes that the housework is the main duty of his wife and invests less time and energy in the family domain, ${ }^{23}$ thereby increasing the wife's family burden. ${ }^{24}$ Meanwhile, wives who hold an egalitarian view are less willing to participate in family duties. In this case, wives' self-expectations concerning the family role are lower than the societal expectations from husbands; therefore, wives find the role demand hard to meet, which can result in role overload. $^{22}$ Thus, our third hypothesis is as follows:

Hypothesis 3 (H3). Wives' role overload is stronger when husbands have a higher level of traditional gender-role attitude than their wives do.

\section{The Relationship Between Role Overload and FIW}

Role theory indicates that strain-based conflict often occurs when there are severe stressors in one domain, such as role overload. ${ }^{21}$ The theory implies a positive relationship between family role overload and FIW. Role overload means that the individual has too many commitments or duties in a period of time. ${ }^{25}$ In the meantime, due to the lack of time and energy to play multiple roles, FIW can occur along the way. ${ }^{21}$ Our fourth hypothesis is as follows:

Hypothesis 4 (H4). The stronger the role overload is, the more FIW the wives will experience. 
Table I Means, Standard Deviations, and Correlations of Study Variables

\begin{tabular}{|l|l|l|l|l|l|l|l|l|l|l|}
\hline Variables & $\mathbf{M}$ & SD & $\mathbf{I}$ & $\mathbf{2}$ & $\mathbf{3}$ & $\mathbf{4}$ & $\mathbf{5}$ & $\mathbf{6}$ & $\mathbf{7}$ & $\mathbf{8}$ \\
\hline I. Relationship duration & 9.76 & 3.69 & - & & & & & & & \\
2. Number of children & 1.79 & 0.69 & $0.23^{* *}$ & - & & & & & & \\
3. Age of youngest child & 3.53 & 3.32 & $0.36^{* *}$ & 0.15 & - & & & & & \\
4. Husbands's WHH & 12.41 & 9.46 & 0.03 & 0.01 & -.01 & - & & & & \\
5. Wives' WHH & 22.65 & 8.87 & 0.04 & -.01 & -.05 & 0.01 & - & & & \\
6. Husbands' TGRA & 2.62 & 0.56 & 0.10 & 0.06 & 0.13 & -.09 & -.02 & $(0.71)$ & & \\
7. Wives' TGRA & 2.33 & 0.74 & 0.09 & 0.12 & 0.09 & 0.03 & 0.14 & -.03 & $(0.90)$ & \\
8. Wives' role overload & 2.97 & 0.60 & 0.10 & 0.08 & 0.14 & 0.00 & 0.08 & $0.33^{* *}$ & $0.3 I^{* *}$ & $(0.86)$ \\
9. Wives' FIW & 3.69 & 1.07 & 0.02 & 0.13 & 0.13 & 0.09 & 0.05 & -.02 & $0.36 * *$ & $0.33^{* *}(0.82)$ \\
\hline
\end{tabular}

Note: $*^{*} p<0.01$.

Abbreviations: WHH, weekly household chores hours; FIW, family interfere with work; TGRA, traditional gender-role attitudes.

Based on the above, it can be concluded that the wives' role overload will mediate the relationship between the congruence of a couple's gender-role attitude and the wife's FIW. This means that, when husband and wife have different gender-role attitudes, the wife might experience an increase in role overload, which will increase her FIW ultimately. The mediating role of role overload was hypothesized as follows:

Hypothesis 5 (H5). Role overload mediates the relationship between husband-wife congruence/incongruence of gender-role attitude and wives' FIW.

\section{Method}

\section{Participants and Procedures}

Data were collected from eight state-owned or private companies operating in the industries of food, machinery, communications, transportation, retail, or electronics in Guangzhou, Mianyang, and Chengdu, China. First, we identified an inside helper from each company who was inclined to recruit the participants from the company for this survey, as well as distributing and collecting questionnaires. After the inside helper for each company was selected, we briefed them on the purpose of this survey, the correct ways of collecting data, and other matters to observe during the survey.

To carry out the survey, the inside helper first gave out questionnaires to married women employees who were willing to participate in the survey. The participants needed to fill in three different questionnaires (related to gender-role attitudes, role overload, and FIW). The inside helper assured them that the results of the survey would be kept confidential, and used only for academic research. Then, the husbands of the participating women received the corresponding questionnaires. The husbands' questionnaire contained a set of questions designed to measure their gender-role attitudes.

We distributed questionnaires to 196 married couples and successfully collected 165 wives' questionnaires and 158 husbands' questionnaires. After removing the questionnaires that had either too many unanswered questions or identical answers in them, we were left with 148 valid husband-wife pairs. The average age of the husbands was 31.86 years $(S D$ $=8.75)$ and that of the wives was $28.39(S D=6.38)$. The results of other demographic variables are shown in Table 1.

\section{Measures}

All English-based measures were translated into Chinese using "translation/back-translation" procedures. The factor structure of those scales was checked by conducted confirmatory factor analyses (CFAs) and the results are reported in the Results section.

\section{Gender-Role Attitudes}

Gender-role attitudes have generally been measured by the extent to which participants hold the traditional view that men should be the breadwinners, and the women should be housewives. Those with a higher score tend to have more traditional gender-role attitudes, while those with a lower score tend to have egalitarian gender-role attitudes. ${ }^{9} \mathrm{We}$ used a five-item scale developed by Livingston and Judge. ${ }^{12}$ An example question was, "A woman's place is in the home rather than the office or shop." Responses were indicated on 4-point scales $(1=$ strongly disagree, 4 $=$ strongly agree). Cronbach's $a$ for this scale was 0.71 for husbands and 0.90 for wives.

\section{Role Overload}

We measured the wives' role overload using Reilly's Role Overload Scale. ${ }^{26}$ The scale consisted of 13 items (eg, 
"There are too many demands on my time") measured with 5-point Likert scales $(1=$ strongly disagree, $5=$ strongly agree). Because we focus on women employees' role in the family domain, we added "at home" to all items for meeting with the context. The scores ranged from 13 to 65 , with higher scores representing more role overload and lower scores representing less role overload. Cronbach's $a$ for this scale was 0.86 .

\section{FIW}

We measured wives' FIW using Netemeyer's FamilyWork Conflict Scale. ${ }^{27}$ The scale consisted of five items (eg, "The demands of my family or spouse/partner interfere with work-related activities") measured with a 5-point Likert scale ( $1=$ strongly disagree, $5=$ strongly agree). Cronbach's $a$ for this scale was 0.82 .

\section{Control Variables}

To isolate the effect of our focal variables on working wives' FIW, we controlled for couples' relationship duration, hours spent doing housework per week, age of the youngest child, and number of children. Such variables have been found to be related to working women's FIW in previous studies. $^{28}$

\section{Analysis}

In order to test $H 1-H 3$, we used polynomial regressions and response surface modeling. ${ }^{29}$ In particular, we first estimated the following equation (to simplify it, we omitted all controlled variables in the presentation):

$$
\begin{aligned}
M= & b_{0}+b_{1} H+b_{2} W+b_{3} H^{2}+b_{4}(H W)+b_{5} F^{2} \\
& +e
\end{aligned}
$$

where $M$ stands for role overload, and $H$ and $W$ for husband and wife's gender-role attitude, respectively. In order to facilitate the interpretation of results, we mean-centered $H$ and $W$ before calculating the second-order terms. Next, in accordance with the regression coefficients estimated by Equation (1), we plotted the three-dimensional response surface in which $H$ and $W$ were plotted on the perpendicular horizontal axes, and $M$ was plotted on the vertical axis. $^{30}$ The results of the polynomial regression are evaluated with regard to four surface test values: $a_{1}, a_{2}, a_{3}$ and $a_{4}$. The slope of the line of congruence (the line where $H=$ $W)$ is given by $a_{1}=\left(b_{1}+b_{2}\right)$, and the curvature by $a_{2}=\left(b_{3}\right.$ $+b_{4}+b_{5}$ ). And the slope of the line of incongruence (the line where $H=-W)$ is given by $a_{3}=\left(b_{1}-b_{2}\right)$, and the curvature by $a_{4}=\left(b_{3}-b_{4}+b_{5}\right)$. Finally, we examined the mediating role of role overload by adopting the block variable approach recommended by ${ }^{30}$ in combination with path analysis.

\section{Results}

Table 1 shows the means, standard deviations, intercorrelations, and reliabilities of the variables.

No control variable is found to be correlated with wives' role overload and FIW. Furthermore, wives' FIW was found to be positively correlated with wives' TGRA $(r=0.36, p<0.01)$, and positively correlated with wives' role overload ( $r=0.33, p<0.01$ ); wives' role overload was also found to be positively correlated with husbands' TGRA $(r=0.33, p<0.01)$, and positively correlated with wives' TGRA $(r=0.31, p<0.01)$.

Prior to testing our hypotheses, we examined whether the constructs assessed in our study were distinguishable from each other. In order to do so, we conducted a confirmatory factor analysis to examine the discriminant validity of the three wife self-reported variables, namely, traditional gender-role attitudes, role overload and FIW. Specifically, each item loaded on its target factor and the measurement errors were uncorrelated. The CFA of a hypothesized three-factor model, including all variables, yielded fit indexes within an acceptable fit $\left(\chi^{2}=312.88, d f\right.$ $=227, \mathrm{RMSEA}=0.05, \mathrm{CFI}=0.93, \mathrm{TLI}=0.92, \mathrm{SRMR}=$ 0.07). We compared these results with those of four alternative models: a one-factor model and 3 two-factor models. Results can be seen from Table 2 that the $\chi^{2}$ of either of the other models shows a significant increase compared to that the three-factor model, and the three-factor model is obviously better in the other fit indices, so we concluded that the three variables represented three distinct constructs that were empirically distinct from each other.

H1 predicts that role overload is higher when husbands and wives are incongruent at the level of TGRA than when they are congruent. The results of the test of $H 1$ are shown in Table 3: $a_{4}$ is significant and positive $\left(a_{4}=0.54, p<0.01\right)$, and also the three second-order polynomial terms are jointly significant in predicting role overload $(F=6.77, p<0.001)$, and they explain significant incremental variance in wives' role overload $\left(\Delta R^{2}=0.07, p<0.01\right)$. Furthermore, the results of bootstrapping analyses revealed that the second principal axis had a slope $\left(p_{21}\right)$ that was not significantly different from 1.0 (95\% CI [- 0.20, 7.49], containing 1), and an intercept $\left(p_{20}\right)$ that was not significantly different from zero (95\% CI [- 0.51, 3.90], containing zero). To interpret 
Table 2 Model Fit Results for Confirmatory Factor Analyses

\begin{tabular}{|c|c|c|c|c|c|c|c|}
\hline Variables & $\chi^{2}$ & $d f$ & $\Delta \chi 2(\Delta d f)$ & RMSEA & CFI & TLI & SRMR \\
\hline I. Three-factor model & 312.88 & 227 & - & 0.05 & 0.93 & 0.92 & 0.07 \\
\hline 2.Two-factor model ${ }^{\mathrm{a}}$ & 502.53 & 229 & $189.65(2)^{* * *}$ & 0.09 & 0.78 & 0.75 & 0.09 \\
\hline 3.Two-factor model ${ }^{b}$ & 746.65 & 229 & $433.77(2)^{* * *}$ & 0.12 & 0.58 & 0.53 & 0.16 \\
\hline 4. Two-factor model ${ }^{c}$ & 556.63 & 229 & $243.75(2)^{* * *}$ & 0.10 & 0.73 & 0.70 & 0.12 \\
\hline 5.Single-factor model & 884.96 & 230 & $572.08(3)^{* * *}$ & 0.14 & 0.46 & 0.41 & 0.14 \\
\hline
\end{tabular}

Notes: $\mathrm{n}=148$. ${ }^{\mathrm{a}}$ Role overload + FIW; TGRA; ${ }^{\mathrm{b}} \mathrm{TGRA}+$ role overload; FIW; ${ }^{\mathrm{c} T G R A}+\mathrm{FIW}$; role overload. All alternative models were compared with the hypothesized three-factor model. All $\Delta \chi 2$ 's are significant at $p<0.001$.

Abbreviations: FIW, family interfere with work; TGRA, traditional gender-role attitudes.

Table 3 Polynomial Regressions of Role Overload on TGRA Congruence

\begin{tabular}{|c|c|c|c|}
\hline Variables & Statistic & Model I & Model 2 \\
\hline Constant & & $2.82 * * *$ & $2.63^{* * *}$ \\
\hline Relationship duration & & 0.00 & 0.00 \\
\hline Number of children & & 0.01 & 0.04 \\
\hline Age of youngest child & & 0.01 & 0.01 \\
\hline Husbands' WHH & & 0.00 & 0.00 \\
\hline Wives' WHH & & 0.00 & 0.00 \\
\hline Husbands' TGRA $(H)$ & $b_{1}$ & $0.36 * * *$ & $0.4 I^{* * *}$ \\
\hline Wives' TGRA (W) & $b_{2}$ & 0.30 *** & $0.18 * *$ \\
\hline$H^{2}$ & $b_{3}$ & & 0.17 \\
\hline$H \times W$ & $b_{4}$ & & -.18 \\
\hline$W^{2}$ & $b_{5}$ & & $0.19 *$ \\
\hline & $R^{2}$ & 0.22 & 0.29 \\
\hline & $\Delta R^{2}$ & & $0.07 * *$ \\
\hline \multicolumn{4}{|c|}{ Congruence line $(H=W)$} \\
\hline & $a_{1}\left(=b_{1}+b_{2}\right)$ & & $0.59 * * *$ \\
\hline & $a_{2}\left(=b_{3}+b_{4}+b_{5}\right)$ & & 0.18 \\
\hline \multicolumn{4}{|c|}{ Incongruence line $(H=-W)$} \\
\hline & $a_{3}\left(=b_{1}-b_{2}\right)$ & & $0.23 *$ \\
\hline & $a_{4}\left(=b_{3}-b_{4}+b_{5}\right)$ & & $0.54 * *$ \\
\hline & $F$ for the 3 & & $0.77^{* * * *}$ \\
\hline & quadratic terms & & \\
\hline
\end{tabular}

Notes: $\mathrm{n}=148$. Unstandardized regression coefficients reported. $*_{\mathrm{p}}<0.05$; ** $\mathrm{p}<$ $0.01 ; * * * p<0.001$.

Abbreviation: TGRA, traditional gender-role attitudes.

these results holistically, the overall response surface using the coefficient estimates was plotted within the data range in Figure 3. As shown in Figure 3, the response surface along the incongruence line is a U-shape one, indicating that wives' role overload is higher when husbands and wives are incongruent at the level of TGRA. Therefore, $H 1$ is verified.

$H 2$ posits that wives' role overload is higher when husbands and wives are aligned at a high level of TGRA than they are at a low level. Table 3 shows that $a_{1}$ is significant and positive $\left(a_{1}=0.59, p<0.001\right)$. After we further checked the response surface, we found that wives' role overload at the rear corner (where $H=W=3$ ) was higher than that at the front corner (where $H=W=-3$ ). $H 2$ is therefore verified.

Furthermore, the response surface in Figure 3 shows wives' role overload at the left corner $(H=-3$ and $W=3)$ is lower than that in the right corner $(H=3$ and $W=-3)$. In addition, we also tested $a_{3}$. As shown in Table 3, it is significant and positive $\left(a_{3}=0.23, p<0.05\right)$. Therefore, $H 3$ is verified.

Regarding the mediating effect, firstly this paper generated a block variable by multiplying the raw data with the regression coefficients estimated by Equation (1). Secondly, this paper examined the indirect relationship between block variables and wives' FIW and the significance of each path coefficient after adding wives' role overload to the model.

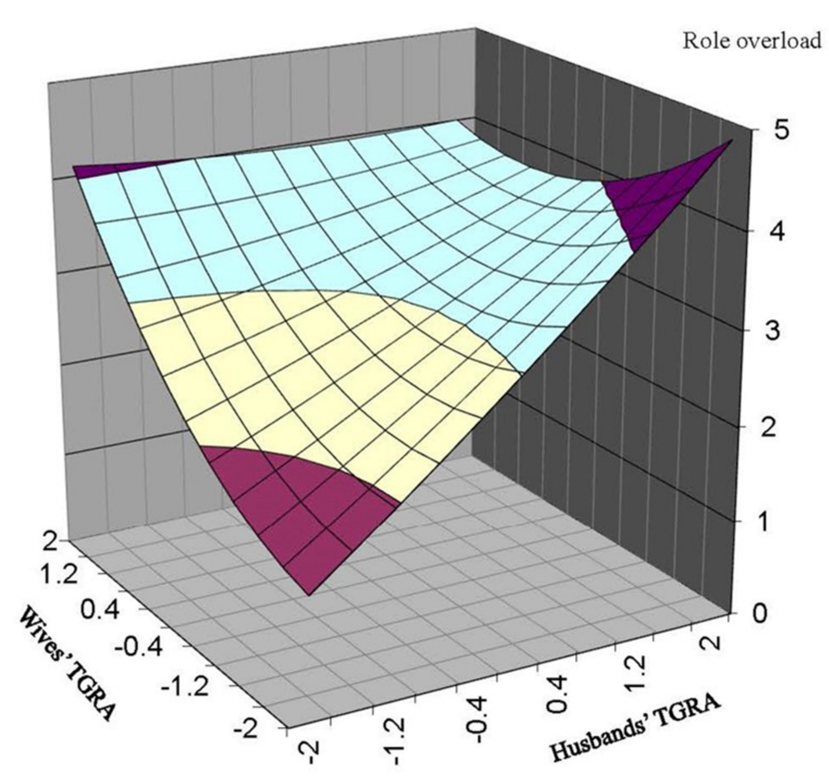

Figure 3 Congruence/incongruence effect of husband-wife traditional gender-role attitudes (TGRA) on wives' role overload. 
Table 4 Results of Mediating Effects Tests

\begin{tabular}{|l|l|l|l|}
\hline Variables & FIW & $\begin{array}{l}\text { Role } \\
\text { Overload }\end{array}$ & FIW \\
\hline $\begin{array}{l}\text { Coefficient of the block } \\
\text { variable } \\
\text { Coefficient of role overload } \\
\text { Mediating effect of role } \\
\text { overload } \\
\text { 95\% bootstrapped Cl } \\
\text { indirect effect }\end{array}$ & $0.23^{* *}$ & $0.53^{* * *}$ & 0.07 \\
\hline
\end{tabular}

Notes: $\mathrm{n}=148$. Standardized regression coefficients reported. ${ }^{* *} \mathrm{p}<0.01 ;{ }^{* * *} \mathrm{p}<$ 0.001 .

Abbreviation: FIW, employees' family interference with work.

As shown in Table 4, before role overload was added, the block variable was positively related to wives' FIW (path $c=0.23, p<0.01$ ), and after it was added, the path coefficient between the block variable and wives' role overload was found to be significant (path $a=0.53, p<0.001$ ). The same was true to the relationship between wives' role overload and FIW (path $b=0.29, p<0.01$ ), and that between the block variable and wives' FIW (path $c^{\prime}=0.07, p=0.42$ ). The mediating effect of wives' role overload on the relationship between husband-wife congruence/incongruence of TGRA and wives' FIW is 0.15 , and the $95 \%$ biascorrected "bootstrap" confidence intervals for it is $(0.05$, 0.27). All these findings show that wives' role overload mediates the indirect relationship between husband-wife congruence/incongruence of TGRA and wives' FIW. The percentage of the mediating effect in the total is $67 \%$. Therefore, H4 is verified (see Table 4).

\section{Discussion}

The objective of the current study was to examine a mediation relationship between husband-wife congruence/incongruence of gender-role attitudes and wife's FIW. The results of polynomial regression analyses supported all the hypotheses. As predicted, guided by the role theory, we found that the husband-wife incongruence of gender-role attitudes augmented wives' role overload and further led to FIW. Our findings have implications for theory and practice.

\section{Theoretical Implications}

First of all, our study provides a theoretical basis to gauge the relationship between congruent gender-role attitudes of married female employees and their husbands and wives' FIW. Recent studies on wives' FIW have been conducted from a single-sided perspective of either the husband or the wife. This paper might partly explain why studies on the relationship between wives' gender-role attitudes and FIW have revealed mixed findings. Some researchers have confirmed the positive correlation between gender-role attitude and FIW. According to an investigation by Kim and Ling, ${ }^{31}$ holding an egalitarian gender-role attitude would help reduce FIW on married women entrepreneurs in Singapore. In another study, Livingston and Judge ${ }^{12}$ pointed out that employees who practiced more traditional gender roles would experience a stronger relationship with FIW. However, there is a controversy about whether wives' traditional gender-role attitudes are negatively related to FIW. $^{7}$ Through a survey of married nurses in Iranian, Namayandeh et $\mathrm{al}^{7}$ found that married female nurses who adopt a more egalitarian gender-role attitude are associated with higher FIW. Thus, prior researches suggest that adopting a dyadic approach considers the role attitudes of spouses could help us understand married employees' role overload. ${ }^{32,33}$ In responding to this call, the present study suggests that the inconsistencies in those researches may be a result of partner-specific approaches that do not allow for the examination of spouse by provider role group in interactions, which would reveal mixed patterns of FIW in different marital contexts.

From the dyadic perspective, our results showed that married women employees experienced more role overload under conditions of couples' gender-role attitudes congruence than incongruence (Hypothesis 1). When had different gender-role attitudes from their husbands, women employees faced with a different role expectation and experienced extra-role pressure. ${ }^{18}$ So their role overload is higher when husbands and wives are incongruent at the level of gender-role attitude than when they are congruent. Our findings offer unique theoretical insights to FIW literature from the husband-wife congruence perspective.

Second, we contribute to the husband-wife fit literature by investigating more complex effects than the simple congruence effect. Specifically, traditional husband-wife fit literature theorizes that the congruence of husband and wife role attitudes leads to better outcomes. ${ }^{17}$ But it does not differentiate between two types of husband-wife congruence and incongruence. By utilizing polynomial regression and response surface methodology, we not only theorized and tested simple congruence effects (Hypothesis 1) but also examined and compared the asymmetric congruence effects of traditional-traditional genderrole attitude versus egalitarian-egalitarian gender-role 
attitude (Hypothesis 2). Compared to an egalitarianegalitarian condition, the wife in a traditional-traditional condition would get less supports from husband, which means that she has to invest much more in the family role. Prior research has found family support can reduce role overload for women in China and Hong Kong. ${ }^{20}$ So we anticipated women in this condition would be more likely to experience role overload than in egalitarian-egalitarian and results supported Hypothesis 2. Another researcher has offered explanations consistent with this notion. ${ }^{9}$ In addition, we also examined the asymmetrical incongruence effects of traditional-egalitarian gender-role attitude versus egalitarian-traditional gender-role attitude (Hypothesis 3). When the husband has a higher level of egalitarian gender-role attitude, the husband tends to shoulder more family duties and wife would get a greater support than wife has a higher level of egalitarian genderrole attitude. ${ }^{9}$ As pointed out earlier, spousal support was negatively related to an individual's role stress in the family domain. ${ }^{21}$ So we anticipated Wives' role overload is stronger when husbands have a higher level of traditional gender-role attitude than their wives do and results supported Hypothesis 3. Married women employees in traditional-egalitarian condition would be most likely to experience role overload than those in other conditions. Consistent with this result, other researchers found that wives in MFTM (traditional female and modern male) reported lower satisfaction than did those in the other groups. ${ }^{34}$ These comparisons offer a more nuanced understanding of congruence and incongruence effects of husband-wife role attitudes in general, thus expanding husband-wife fit literature by illuminating more complex effects.

Third, we contribute to the husband-wife fit literature by using it as a guiding theory in the work-family field and identifying role overload as a new relational mechanism that transits congruence in husband-wife gender-role attitudes to wife's FIW. Few past researches on husband-wife congruence have examined mediating processes. This study involves the role theory in revealing the mediating effect of wives' role overload on the relationship between husband-wife congruence/incongruence of TGRA and wives' FIW (Hypothesis 4). Compared with the congruent condition, the wives who are in the incongruent condition, because they feel more demands, are more likely to experience the role overload, thus further experiencing FIW. This result supports the view that "role strain occurs when a lack of agreement is made between occupants of complementary roles in a family". ${ }^{17}$

Finally, most previous congruent studies have focused on areas of person-organization fit, person-vocation fit, person-group $\mathrm{fit}^{35}$ and leader-follower fit. ${ }^{36}$ Based on the finding that the work and family domains are closely related, ${ }^{37}$ researchers should examine the relationship between husband-wife congruence and the wife's workplace outcome.

However, few studies covered husband-wife fit. ${ }^{17,35}$ This study, therefore, extends congruence studies by focusing on the relationship between husband-wife congruence and FIW.

\section{Practical Implications}

This study also has practical implications for organizations and working women. From an organizational perspective, our finding implies that managers should be aware that it may be difficult for some working wives to abandon family responsibilities. Managers should be open to different value systems of women and offer adequate and appropriate support to help them strike a balance between family and work. For example, managers may adopt a more flexible work schedule that enables these wives to have the time they need to deal with their family. As for women employees, they should be aware of the negative relationship between the husband-wife congruence of gender-role attitudes and their FIW so that they can attempt to establish good couple relationships.

\section{Limitations and Future Research}

This study has some limitations. First, we were unable to make causal inferences from the data due to the crosssectional nature of the study. Therefore, a longitudinal perspective is highly recommended for future research on gender-role attitudes. An interesting question is whether the significant correlation in the present study reflects the effect of wives' FIW on couple's congruence of genderrole attitudes. Moreover, whether the relationship is caused by other factors? For example, working wives' marital satisfaction has been related to the couple's congruence of gender-role attitudes ${ }^{35}$ and work-family conflict. ${ }^{38}$ Future researches should examine the role of marital satisfaction in the relationship between couple's congruence of gender-role attitudes and FIW.

Second, although the study has successfully found out the complicated relationship between the congruence of couples' gender-role attitudes and the FIW for the married working 
women. Prior research has shown that the couple's congruence of gender-role attitudes has a different effect on husband from wife. ${ }^{39}$ Therefore, whether there would be some similar findings on husbands need to be further studied.

Third, considering that almost all the scales in this study were measured by self-report, another limitation could be the subjectivity and social desirability proneness. Future research may benefit from assessing these variables with more objective measures.

Finally, this study did not explore whether different work and family scenarios can moderate the indirect relationship between the congruence of couples' gender-role attitudes and wives' FIW. Studies have shown that raising a child with an anxious attachment style might send the mother particularly strong signals of need for care and support, ${ }^{40}$ which further increases the wives' family burden when in an incongruent situation. Therefore, future studies may further explore the moderating mechanism from this perspective.

\section{Conclusions}

The current study advances research on the FIW of married female workers by suggesting a more complex approach that considers the congruence of gender-role attitude between a working wife and her husband. We drew from the role theory ${ }^{16}$ and adopted the polynomial regression and response surface methodology to examine the complicated relationship between husband-wife congruence effect of gender-role attitudes and wives' FIW and role overload in mediating such relationship. The study found that wives' role overload was lower when husbands and wives were congruent in terms of gender attitudes than otherwise. Concretely, the low-low congruence condition had lower wives' role overload than the high-high congruence condition. In the incongruence scenario, the wives' role overload was higher when wives had a higher level of traditional gender-role attitudes than that of their husbands, and the wives' role overload mediated the relationship between the congruence of couples' gender-role attitudes and wives' FIW.

\section{Ethics and Consent Statement}

All procedures performed in studies involving human participants were in accordance with the ethical standards of the Ethics Committee of Management School of Jinan University and with the 1964 Helsinki Declaration and its later amendments or comparable ethical standards. This study was done with the permission of the companies involved.

\section{Informed Consent}

Informed consent was obtained from all individual adult participants included in the study.

\section{Author Contributions}

All authors contributed to data analysis, drafting or revising the article, have agreed on the journal to which the article will be submitted, gave final approval of the version to be published, and agree to be accountable for all aspects of the work.

\section{Funding}

This research was supported by the Foundation Major Cultivation Project of Guangdong Province, China (No. 2017A030308013).

\section{Disclosure}

The authors declare no conflict of interest.

\section{References}

1. Davidson MJ, Burke RJ. Women in Management Worldwide: Facts, Figures and Analysis. Aldershot: Ashgate; 2004.

2. Craig L, Mullan K. Parenthood, gender and work-family time in the United States, Australia, Italy, France, and Denmark. J Marriage Fam. 2010;72(5):1344-1361. doi:10.1111/j.1741-3737.2010.00769.x

3. Arendell T. Conceiving and investigating motherhood: the decade's scholarship. J Marriage Fam. 2000;62(4):1192-1207. doi:10.1111/ j.1741-3737.2000.01192.x

4. Greenhaus JH, Beutell NJ. Sources of conflict between work and family roles. Acad Manage Rev. 1985;10(1):76-88. doi:10.5465/ amr.1985.4277352

5. Hwang S, Firfiray S. Work-family conflict, work engagement and satisfaction: a diary study of solicitors in the UK. Acad Manag Proc. 2018;2018(1):15372. doi:10.5465/AMBPP.2018.15372abstract

6. Zhao XR, Qu H, Ghiselli R. Examining the relationship of workfamily conflict to job and life satisfaction: a case of hotel sales managers. Int $J$ Hosp Manag. 2011;30(1):46-54. doi:10.1016/j. ijhm.2010.04.010

7. Namayandeh H, Yaacob SN, Juhari R. The effect of gender role orientation on work interference with family (WIF) and family interference with work (FIW) among married female nurses in Shiraz-Iran. Cult Hist Digit J. 2010;2(2):165-171.

8. Brogan D, Kutner NG. Measuring sex-role orientation: a normative approach. J Marriage Fam. 1976;38(1):31-40. doi:10.2307/350548

9. Steiner RS, Krings F, Wiese BS. Remember the children, honey! Spouses' gender-role attitudes and working mothers' work-to-family conflict. Appl Psychol. 2019;68(2):250-275. doi:10.1111/apps.12160

10. Spector PE. Job Satisfaction: Application, Assessment, Causes, and Consequences. Thousand Oaks: Sage; 1997.

11. Hochschild A, Machung A. The Second Shift. New York: Avon Books; 1989.

12. Livingston BA, Judge TA. Emotional responses to work-family conflict: an examination of gender role orientation among working men and women. J Appl Psychol. 2008;93(1):207-216. doi:10.1037/00219010.93.1.207

13. Shimazu A, Kubota K, Bakker A, et al. Work-to-family conflict and family-to-work conflict among Japanese dual-earner couples with preschool children: a spillover-crossover perspective. J Occup Health. 2013;55(4):234-243. doi:10.1539/joh.12-0252-OA 
14. Isa NM, Kaur H, Singh PL, Hashim R. Job stress, work-to-family conflict and social support in the education industry. J Adam Sci. 2018;15(3):1-17.

15. Rizzo JR, House RJ, Lirtzman SI. Role conflict and ambiguity in complex organizations. Admin Sci Quart. 1970;15(2):150-163. doi: $10.2307 / 2391486$

16. Sarbin TR, Allen VL. Role theory. In: Lindzey G, Aronson E, editors. The Handbook of Social Psychology,2nd ed., Vol. 1. MA: AddisonWesley; 1968:488-567.

17. Chassin L, Zeiss A, Cooper K, Reaven J. Role perceptions, self-role congruence and marital satisfaction in dual-worker couples with preschool children. Soc Psychol Quart. 1985;48(4):301-311. doi:10.23 07/2786692

18. Hiller DV, Philliber WW. Predicting marital and career success among dual-worker couples. J Marriage Fam. 1982;44(1):53-62. doi: $10.2307 / 351262$

19. Ostrow AC, Jones DC, Spiker DD. Age role expectations and sex role expectations for selected sport activities. Res $Q$ Exercise Sport. 1981;52(2):216-227. doi:10.1080/02701367.1981.10607860

20. Drummond S, Driscoll MP, Brough P, et al. The relationship of social support with well-being outcomes via work-family conflict: moderating effects of gender, dependants and nationality. Hum Relat. 2017;70(5):544-565. doi:10.1177/0018726716662696

21. Michel JS, Kotrba LM, Mitchelson JK, Clark MA, Baltes BB. Antecedents of work-family conflict: a meta-analytic review. J Organ Behav. 2011;32(5):689-725. doi:10.1002/job.695

22. Hall MEL, Duvall NS. Married women in missions: the effects of cross-cultural and self gender-role expectations on well-being, stress, and self-esteem. J Psychol Theol. 2003;31(4):303-314. doi:10.1177/ 009164710303100401

23. Davis SN, Greenstein TN. Gender ideology: components, predictors, and consequences. Annu Rev Sociol. 2009;35(1):87-105. doi:10.1146/annurev-soc-070308-115920

24. McHale SM, Crouter AC. You can't always get what you want: incongruence between sex-role attitudes and family work roles and its implications for marriage. J Marriage Fam. 1992;54(3):537-547. doi: $10.2307 / 353240$

25. Gurbuz S, Turunc O, Celik M. The impact of perceived organizational support on work-family conflict: does role overload have a mediating role? Econ Ind Democracy. 2013;34(1):145-160. doi:10.1177/0143831X12438234

26. Reilly MD. Working wives and convenience consumption. J Consum Res. 1982;8(4):407-418. doi:10.1086/208881

27. Netemeyer RG, Boles JS, McMurrian R. Development and validation of work-family conflict and family-work conflict scales. J Appl Psychol. 1996;81(4):400. doi:10.1037/0021-9010.81.4.400
28. Byron K. A meta-analytic review of work-family conflict and its antecedents. J Vocat Behav. 2005;67(2):169-198. doi:10.1016/j. jvb.2004.08.009

29. Edwards JR, Parry ME. On the use of polynomial regression equations as an alternative to difference scores in organizational research. Acad Manage J. 1993;36(6):1577-1613.

30. Edwards JR, Cable DM. The value of value congruence. J Appl Psychol. 2009;94(3):654. doi:10.1037/a0014891

31. Kim JLS, Cs L. Work-family conflict of women entrepreneurs in Singapore. Women Manag Rev. 2001;16(5):204-221. doi:10.1108/ 09649420110395692

32. Helms HM, Walls JK, Crouter AC, McHale SM. Provider role attitudes, marital satisfaction, role overload, and housework: a dyadic approach. J Fam Psychol. 2010;24(5):568. doi:10.1037/ a0020637

33. Helms HM, Proulx CM, Klute MM, McHale SM, Crouter AC. Spouses' gender-typed attributes and their links with marital quality: a pattern analytic approach. J Soc Pers Relat. 2006;23(6):843-864. doi:10.1177/0265407506068266

34. Cao H, Li X, Chi P, et al. Within-couple configuration of genderrelated attitudes and its association with marital satisfaction in Chinese marriage: a dyadic, pattern-analytic approach. J Pers. 2019;87(6):1189-1205. doi:10.1111/jopy.12467

35. Atwater L, Dionne S. A process model of leader-follower fit. In: Ostroff C, Judge TA, editors. Perspectives on Organizational Fit. Mahwah, NJ: Erlbaum; 2007:183-208.

36. Johnson RE, Lin S-HJ, Kark R, et al. Consequences of regulatory fit for leader-follower relationship quality and commitment. Journal of Occupational and Organizational Psychology. 2017;90(3):379-406. doi:10.1111/joop. 12176

37. Peplau LA. Roles and gender. In: Kelley HH, Berscheid E, Christensen A, Harvey JH, editors. Close Relationships. New York: W. H. Freeman; 1983:220-264.

38. Minnotte KL, Minnotte MC, Bonstrom J. Work-family conflicts and marital satisfaction among US workers: does stress amplification matter? J Fam Econ Iss. 2015;36(1):21-33. doi:10.1007/s10834014-9420-5

39. Liang Y. Gender role attitude congruence moderates the relationship between OCB and work-family conflict. Acad Manag Proc. 2017;2017(1):14753. doi:10.5465/AMBPP.2017.14753abstract

40. Fraley RC, Heffernan ME, Vicary AM, Brumbaugh CC. The experiences in close relationships - relationship structures questionnaire: a method for assessing attachment orientations across relationships Psychol Assessment. 2011;23(3):615. doi:10.1037/a0022898
Psychology Research and Behavior Management

\section{Publish your work in this journal}

Psychology Research and Behavior Management is an international, peer-reviewed, open access journal focusing on the science of psychology and its application in behavior management to develop improved outcomes in the clinical, educational, sports and business arenas. Specific topics covered in the journal include: Neuroscience, memory and decision making; Behavior modification and management; Clinical applications; Business and sports performance management; Social and developmental studies; Animal studies. The manuscript management system is completely online and includes a very quick and fair peer-review system, which is all easy to use. Visit http://www. dovepress.com/testimonials.php to read real quotes from published authors. 